\title{
BAIRROS RURAIS PAULISTAS: CASCALHO E SANTANA
}

\author{
Cibele Marto de OLIVEIRA \\ Marcela Bianca Malosso GRAÇA
}

\section{Resumo}

Este trabalho descreve e identifica aspectos relativos a forma, aos processos, a estrutura e a função cumprida pelos bairros rurais de Cascalho, localizado no município de Cordeirópolis - SP e Santana, situado no município de Piracicaba- SP. O procedimento metodológico consiste em revisão bibliográfica sobre o recorte espacial de bairro rural, na realização de trabalhos de campo e na produção de entrevistas com os moradores dos bairros. Desta forma foi possível analisar os elementos sociais e culturais, acrescidos dos econômicos com a finalidade relatar as principais características e mudanças ocorridas em decorrência da transformação do espaço em mais de um século de existência de Cascalho e Santana.

Palavras-chave: Bairro rural. Organização espacial. Relação campo cidade.

\section{Resumen}

\section{Barrios rurales paulistas: Cascalho y Santana}

Este trabajo describi e identifica aspectos relativos a la forma, proceso, estructura y función de los barrios rurales de Cascalho, ubicado en el municipio de Cordeirópolis SP y Santana, situado en el municipio de Piracicaba-SP. El procedimiento metodológico consiste en revisión bibliográfica sobre el recorte espacial de barrio rural, en la realización de trabajos de campo y en la producción de entrevistas con los moradores de los barrios. Así fue posible analizar los elementos sociales y culturales, añadidos de los económicos con la finalidad de relatar las principales características y cambios ocurridos como consecuencia de la transformación del espacio en más de un siglo de existencia de Cascalho y Santana.

Palavras-clave: Barrio rural. Organización espacial. Relación campo ciudad.

\footnotetext{
1 Doutoranda do Programa de Pós-Graduação em Geografia da Universidade Estadual Paulista "Júlio de Mesquita Filho" - UNESP/Rio Claro. E-mail: martocibele@yahoo.com.br

2 Mestranda do Programa de Pós-Graduação em Geografia da Universidade Estadual Paulista "Júlio de Mesquita Filho" - UNESP/Rio Claro. E-mail: marcelagraca@yahoo.com.br
} 


\section{INTRODUÇÃO}

O presente trabalho parte da discussão do conceito de bairros rurais para efetuar a análise de dois deles, Cascalho, situado no município de Cordeirópolis e Santana, localizado em Piracicaba- SP. O objetivo foi identificar as estratégias econômicas e sociais dos moradores a partir das categorias analíticas: forma, processo, estrutura e função como meio de compreender as transformações desses lugares depois de mais de um século de existência. Essa análise vai ao encontro do que afirma Côrrea (1986), que acredita que o estudo da sociedade é viabilizado por meio da sua organização espacial, constituída pelo conjunto de objetos criados e dispostos na superfície pelos homens.

Os bairros foram constituídos por imigrantes italianos que chegaram ao Brasil a partir da década de 1880, outro ponto semelhante é que se basearam no princípio em atividades agrícolas, mas em consequência das transformações ocorridas no campo e com a modernização da agricultura brasileira, outras atividades e meios de sobrevivência passaram a ser adotados, fazendo com que os produtores rurais, no decorrer da história, buscassem outras ocupações de trabalho e outras fontes de obtenção de renda também na cidade.

Os procedimentos utilizados para a pesquisa foram revisão bibliográfica sobre o conceito de bairro rural, a realização de trabalhos de campo para observação e conhecimento de aspectos do meio físico, social e econômico e também a produção de entrevistas com os moradores para obtenção de dados e informações históricas.
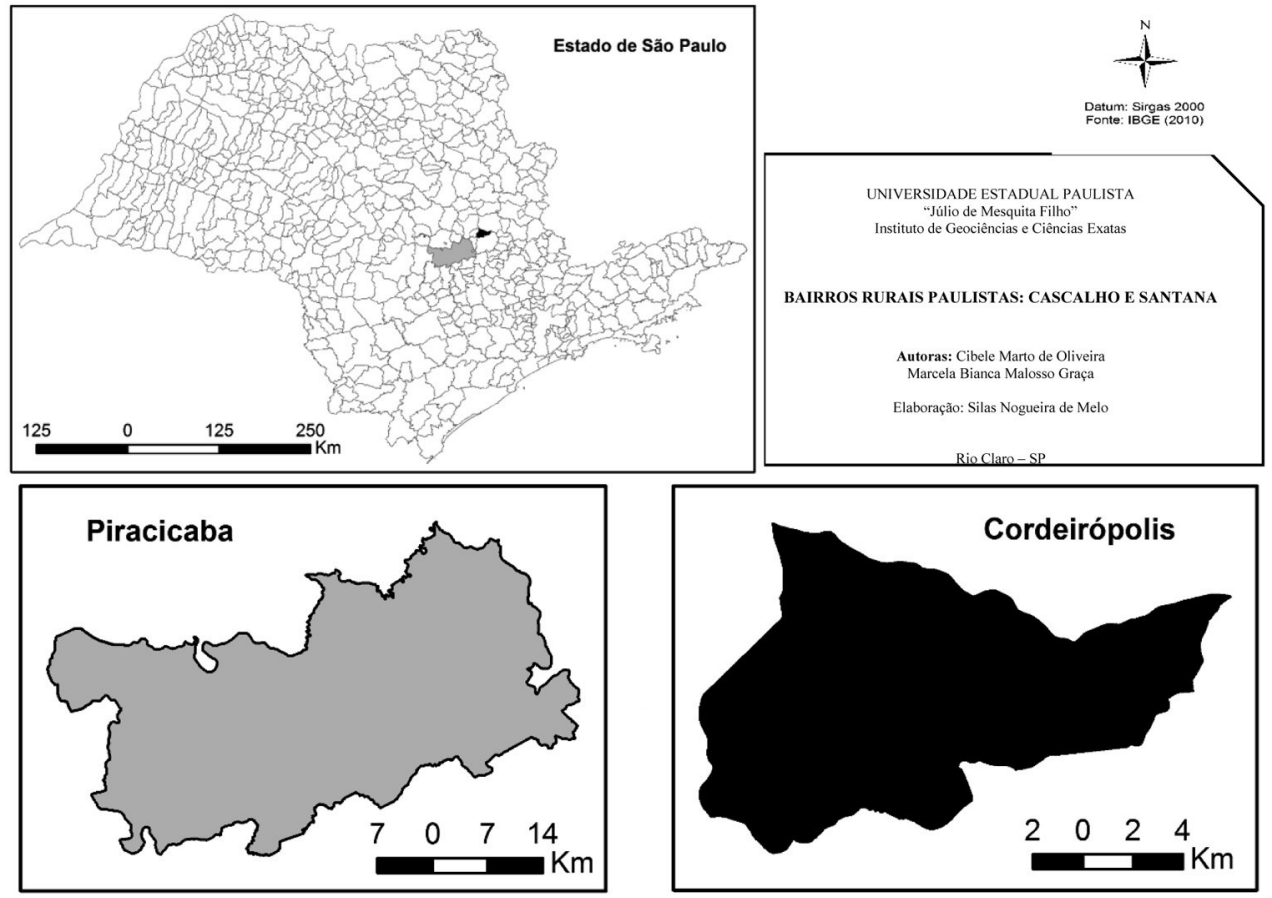

Figura 1 - Localização dos Munícipios de Cordeirópolis e Piracicaba 


\section{BAIRROS RURAIS PAULISTAS}

Historicamente a definição e uso do termo "bairro rural" é restrita ao Estado de São Paulo e ao sul de Minas Gerais, em áreas de influência do estado paulista. Se trata de uma forma regional de organização do habitat, que apesar de ter formação semelhantes em outras áreas do país, não recebem a mesma designação (FERNANDES, 1972; MÜLLER, 1966).

De acordo com Candido (2010), essa formação aconteceu inicialmente pelos denominados caipiras, tendo como característica uma proximidade maior das casas e uma organização comunitária, em comparação à dispersão que havia predominado no país até o século XIX. Posteriormente, passaram, também, a ser constituídos por populações de imigrantes estrangeiros e seus descendentes, como no caso dos bairros aqui analisados.

A formação e aumento de bairros rurais foi possível devido à política de terras do Estado de São Paulo, pautada na colonização, imigração e trabalho, visando subsidiar os setores ligados à grande lavoura de café. Antes dessa política de terras, o termo foi amplamente difundido para indicar determinada porção de território, de limites nem sempre muito precisos, definidos geralmente em função do sentimento de localidade. O bairro rural é, portanto, uma unidade social e espacial que fez parte do processo evolutivo do espaço paulista interiorano quando esse passou a ser explorado de forma intensa pelas grandes monoculturas (GADELHA, 1982; FERNANDES, 1972).

Ainda sobre o conceito do termo, Nice Lecocq Müller (1966), define o bairro como sendo todo conjunto de casas, suficientemente próximas para que se estabeleçam contatos sociais e de entreajuda entre seus moradores, tendo entre eles certos tipos de parentesco e de vizinhança. Geralmente a existência de comércios, escola e a prática da religiosidade reforçam o raio de ação e laços sociais, demarcando seus limites. Devido ainda não ter muita diferença entre as classes sociais, essa condição igualitária permitiu o desenvolvimento do trabalho comunitário coletivo, o mutirão, que é praticado ainda hoje em função da realização das festas e de maneira mais pontual quando acontece alguma obra específica da igreja.

Outro aspecto acerca do bairro rural é a existência de um núcleo, formado a partir da edificação da igreja católica. De maneira geral podemos apontar que os bairros rurais possuem como características comuns: agrupamento de famílias, grupos de vizinhança, posse das terras, auxílio/mutirão, sentimento de localidade, práticas de atividade lúdico-religiosas, unidade social e espacial, realização de festas em prol da igreja católica e ausência, ou abrandamento da estratificação social. Portanto, não são os componentes do meio físico que determinam essa unidade, esse aspecto até pode ser considerado em um primeiro momento ao se constituir um, porém os elementos afetivos é que o determinam.

\section{ASPECTOS GERAIS SOBRE OS BAIRROS DE CASCALHO E SANTANA: A FORMA ESPACIAL}

A forma espacial diz respeito ao aspecto do visível, do exterior de um objeto, de seu arranjo na superfície (CÔRREA, 1986; SANTOS, 1985).

Cascalho e Santana são distantes aproximadamente 35 quilômetros, tendo, portanto, muitas características relacionadas à geografia física em comum. Em ter- 
mos geomorfológicos os bairros fazem parte da Depressão Periférica Paulista, em área pertencente à Zona do Médio Tietê ${ }^{3}$ (CEAPLA, 2011). A Depressão Periférica é uma região que abrange, aproximadamente, $47.000 \mathrm{Km}^{2}$, cerca de $19 \%$ de área do Estado de São Paulo com altitudes que variam de 500 a $700 \mathrm{~m}$. São áreas rebaixadas e aplanadas, com relevo pouco desgastado. Há predomínio de clima quente e úmido e manchas de solos férteis recoberto por densa rede de drenagem (DINIZ, 1969; ROSS, 2009).

O clima de Cascalho e Santana é o Cwa de acordo com a classificação de Köppen, caracterizado por ser quente com inverno seco e verão chuvoso. Marcado por um período de estiagem muito nítido, no qual a frequência da pluviosidade diminui consideravelmente tendo como resultado uma das áreas de inverno mais seco do Estado de São Paulo. Considerando a latitude e altitude, verifica-se que as temperaturas médias anuais variam entre $18,1^{\circ} \mathrm{C}$ a e $20,9^{\circ} \mathrm{C}$. No mês de janeiro, a variação ocorre entre as médias de $20^{\circ} \mathrm{C}$ e $23,7^{\circ} \mathrm{C}$. Em julho as médias distribuem-se entre $14,9^{\circ} \mathrm{C}$ e $17,1^{\circ} \mathrm{C}$ (CEAPLA, 2011; ROLIM et. al, 2007).

A existência dos lugares requerem um equilíbrio entre as necessidades da população residente e os recursos existentes no meio. Quando os bairros foram formados, de acordo com as necessidades da época, eles se caracterizavam economicamente pela produção de gêneros atrelados ao autoconsumo. Houve uma adaptação dos cultivos em função dos hábitos da população em relação ao clima, tipo de relevo e solo. Não foi possível o plantio do trigo e da uva, que eram base para produção de alimentos e do vinho. Dessa forma, passaram a consumir uma quantidade maior de alimentos produzidos a partir do milho e fabricar o vinho com a laranja quando não conseguiam adquirir uva.

As marcas da cultura também estão evidenciadas nos bairros por meio da prática religiosa. O catolicismo é a única religião praticada de forma notória em Cascalho e Santana. Os aspectos vivíveis e invisíveis se fazem presente nas edificações, na simbologia e também na sonoridade dos sinos, rezas e procissões.

O comércio nos bairros é restrito, pois ainda há uma dependência em relação à cidade para fazer compras, aquisições e utilização do setor de serviços. Essa relação entre os espaços do campo e da cidade se estreitaram no decorrer da história e se mantêm até a atualidade.

\section{ASPECTOS dA FORMAÇÃo de CASCALHO E SANTANA: PROCESSO de TRANSFORMAÇÃO}

O processo de transformação diz respeito a ação que se realiza continuamente, evidenciando uma estrutura em seu movimento de transformação (CÔRREA, 1986; SANTOS, 1985).

A formação populacional dos bairros aconteceu por meio da imigração italiana, principalmente. A condição de absorver a mão-de-obra europeia adveio em função da Europa "expulsar" grande contingente de sua população no século XIX, em decorrência do sistema capitalista que se implantava, proibindo ao camponês o usufruto dos bens comunitários e colocando-o sob o domínio da propriedade privada, o que provocou uma enorme emigração (GADELHA, 1982).

\footnotetext{
3 Essa zona trata-se de uma divisão tríplice adotada por Almeida (1974) constituída pela Zona do Médio Tietê, Zona do Paranapanema e Zona do Mogi Guaçu.
} 
A imigração europeia para o Brasil contribuiu para o povoamento e adensamento de algumas vilas e cidades existentes na época, principalmente na Província de São Paulo e na região Sul do país. No especifico processo histórico de formação dos bairros pesquisados, a imigração de população italiana trouxe a importância da constituição familiar, a dedicação ao trabalho e a prática da religiosidade. Legados que ainda permanecem com as famílias que vivem por lá.

A cana-de-açúcar foi o primeiro cultivo nas terras pertencentes ao atual município de Cordeirópolis. A partir desse produto foi possível o desenvolvimento de uma infraestrutura na área (LOMBARDO, 1978). Na década de 1850 a cana foi substituída pelo café como produto comercial de exportação, época que surgiu o Núcleo Colonial de Cascalho criado pela então Província de São Paulo no ano de 1885, a partir das terras adquiridas da Fazenda Cascalho, produtora de café. Além dos moradores do Núcleo trabalharam como mão-de-obra nas grandes fazendas de café, eles cultivavam várias espécies para consumo da família e vendiam os excedentes pela região. Os principais plantios do bairro eram: café, milho, arroz, feijão, algodão, amendoim ${ }^{4}$, frutas e mandioca. Produziam ainda: ovos, leite, banha, linguiças e queijos.

O Núcleo foi emancipado por meio do Decreto n. 225 A de 30 de dezembro de 1893, data que a retirada do Governo como autoridade e interrompendo os recursos financeiros. Após a emancipação se conservaram ali a grande parte da população que já estava instalada, tendo como ocupação a continuação do trabalho como agricultor, principalmente (BOTTEON, 2005).

Lombardo (1978) pontua que a comercialização de café em Cascalho durou até a década 1920, quando a crise tornou inviável a continuidade do plantio e as propriedades agrícolas tiveram que se adaptar a outros tipos de produtos comerciais como policultura, a produção da seda e a citricultura. Nas décadas entre 1930 e 1950 havia no lugar uma diversidade de comércios e pequenas fábricas. Assim sendo, Cascalho precisou diversificar as culturas plantadas em suas terras ao longo do século XX e início do século XXI como forma de se adaptar e atender as demandas do mercado, consequentemente a relação com a cidade se estreitou e muitas das tradições e costumes do Bairro foram sucumbindo em meio as transformações do espaço e mudanças de ordem social e econômica, refletindo diretamente no modo de vida rural.

A história do Bairro de Santana também é associada ao processo imigratório do Brasil. Como aconteceu em todo o Estado de São Paulo, a grande maioria veio para trabalhar no campo, principalmente com o cultivo do café nas grandes fazendas. Os antigos imigrantes do bairro vieram da região de Trento, localizado ao Norte da Itália, lugar que há uma mescla da cultura ítalo-germânica, sendo os trentinos também chamados por tiroleses ${ }^{5}$ (LEOPOLDINO, 2014).

As terras onde está o Bairro faziam parte da Fazenda Sant'Anna de propriedade do Barão de Serra Negra, que adquiriu muitas dívidas e seus descendentes não conseguiram quitar, levando a propriedade a ficar em poder do banco que as vendeu. Em 1893, a família de Bortolo Vitti, imigrante italiano residente no Brasil já alguns anos, adquiriu as terras, cerca de 350 alqueires que na ocasião da compra estavam abandonadas. Devido à religiosidade do grupo e por serem devotos de Nossa Senho$\mathrm{ra}$, deixaram que permanecesse o nome de Santana (ULRICH, 2002).

\footnotetext{
${ }^{4}$ Cascalho foi um grande produtor dessa cultura nas primeiras décadas do século XX. Era plantado intercalado com os corredores dos pés de café.

5 O termo tirolês os caracterizou por serem um grupo étnico, descendentes de imigrantes (camponeses) oriundos do Tirol, uma região que fazia parte do Império Austro-húngaro que após a Primeira Guerra Mundial, em 1919, passou a ser parte da Itália com o nome de Trento, através do tratado de Saint German" (LEME, 2001, p. 01).
} 
Desde a chegada dos imigrantes e com a fundação do Bairro Santana na década de 1940, muitas das tradições foram mantidas em função do isolamento do lugar, distante aproximadamente 20 quilômetros do centro do município de Piracicaba. Devido ao difícil acesso, houve pouco envolvimento dos moradores de Santana com pessoas que não fossem da comunidade. Essa condição refletiu diretamente na conservação das tradições.

Os primeiros moradores do bairro plantavam espécies para o próprio consumo e o café, que foi posteriormente substituído por culturas variadas, como milho, arroz e cana-de-açúcar. As famílias também sempre criaram animais, principalmente galinhas, porcos e vacas.

Houve também no decorrer da história do Bairro outras experiências de cultivos. Na década de 1940 foi o eucalipto e o algodão, tentativas que também não deram certo. No caso do eucalipto faltou conhecimento de técnicas corretas e o algodão não foi rentável. Nas décadas de 1930 e 1970 houve a criação do bicho da seda. Em ambas ocasiões a atividade não teve êxito e causou vários prejuízos (LEOPOLDINO, 2014; LEME, 2001). Em função da proximidade geográfica, das condições do solo e da falta de meios de transportes fizeram com que prevalecesse no Bairro, após o cultivo de café até 1930, o plantio de cana de açúcar, que tinha destino certo, a maior parte ia para a Usina Costa Pinto, pertencente atualmente ao grupo Raízen ${ }^{6}$. Essa situação prevalece até hoje.

\section{ESTRUTURA: DETALHANDO E DESCREVENDO}

A estrutura é atrelada ao modo como os objetos estão organizados a partir da natureza social e econômica de uma sociedade em dado momento e espaço (CÔRREA, 1986; SANTOS, 1985).

O bairro de Cascalho localiza-se na parte centro-oeste do município de Cordeirópolis e fica próximo de três rodovias importantes do Estado de São Paulo: Washington Luís (SP-310); Rodovia dos Bandeirantes (SP-348) e Rodovia Anhanguera (SP-330). O bairro é ainda entrecortado pela Rodovia Constantine Peruche (Cordeirópolis - Rio Claro/SP-316). A proximidade de Cascalho com o núcleo urbano de Cordeirópolis oportuniza atualmente uma intensa relação, tanto no âmbito econômico como social.

Devido as recorrentes divisões de terras que aconteceram nas propriedades, por partilhas de herança e loteamentos, muitas acabaram se tornando chácaras de lazer, deixaram de produzir para a agropecuária. Houve também inúmeras trocas de áreas de cultivo e criação de animais por instalação de comércios, empresas, indústrias e cultivo de plantas ornamentais. No bairro há hoje loteamentos irregulares com casas já construídas e inacabadas e instalação de comércio que funcionam de forma clandestina.

As industrias cerâmicas instaladas em Cascalho causam degradação ao meio ambiente e prejudicam a produção de algumas espécies. Caso emblemático dessa conjectura é em relação ao cultivo de abacate, que por precisar de pouca água tinha no bairro as condições perfeitas para o seu desenvolvimento, porém sua produção tem sido prejudicada pela contaminação causada no ar.

${ }^{6}$ Empresa brasileira de produção de etanol e açúcar. n.a. 
Dentre todos os cultivos destinados ao mercado, somente as plantas ornamentais, produção de orgânicos ${ }^{7}$ e de mudas de abacate são irrigados com água da captação dos poços artesianos das propriedades onde são cultivados. O cultivo de plantas ornamentais existe no bairro desde o final da década de 1970, é uma produção que tem se mostrado promissora ocupando aproximadamente 50 ha com mais de 300 espécies $^{8}$ cultivadas.

A pouca quantidade de culturas irrigadas ocorre pela indisponibilidade de água no bairro, que sempre foi um problema sendo o Rio Tatu o único da região com maior vazão de água. Esse Rio nasce área rural de Cordeirópolis, segue percurso pelo município de Limeira e desagua no Rio Piracicaba. Há em Cascalho uma represa que abastece todo o município de Cordeirópolis ${ }^{9}$. Existe a intenção de se construir uma segunda, pois a primeira e está no limite da capacidade e demanda uma rápida implementação.

A energia elétrica chegou ao lugar em 1914, mas até hoje a iluminação das vias públicas é exclusiva do núcleo do bairro e ruas próximas a ele. Cascalho ainda não possui saneamento básico e o abastecimento feito pela Represa não possui tratamento, o que leva os moradores continuarem a usar a água dos poços artesianos.

Parte da economia do bairro é gerada atualmente pela realização de festas e eventos, não só da comunidade católica, mas também por inúmeros proprietários e empresas que os realizam em sítios e chácaras alocados com essa finalidade. Voltados ao entretenimento e lazer há três pesqueiros e dois campos de bocha, um que funciona no fundo de um dos bares e o outro no Clube e Esportes da Paróquia de Cascalho.

No ano de 2016 foi reinaugurado o Posto de Saúde. A mudança de local dessa unidade de saúde aconteceu devido a construção de prédio próprio da prefeitura. Foi construída uma sala para funcionamento de consultório dentário, serviço ainda não implementado. Cascalho também possui a instalação de pequenas fábricas e alguns comércios, como de lojas de plantas ornamentais, loja de produtos orgânicos, restaurantes, bares, peixaria e uma pequena mercearia. Desde o ano de 2014 funciona uma unidade comunitária de Agência dos Correios. Essa pouca expressão comercial é explicada em partes pela relação que o bairro mantém com a área urbana.

Sobre as mudanças de ordem social foram muitas. Uma das características mais marcante do bairro rural, o mutirão, deixou de ser praticado em atividades voltadas à agropecuária, ficando restrito à execução das festas promovidas pela igreja católica.

O bairro rural de Santana fica a noroeste do centro do município de Piracicaba e está distante cerca de 20 quilômetros do centro. Como acesso há somente uma rodovia estadual, a Hermínio Petrin (SP-308).

Em 1977, os trentinos de Piracicaba comemoraram o Centenário da Imigração de seus antepassados e organizaram uma grande festa, que desde então passou a fazer parte do calendário de eventos do bairro. Foi por meio desse evento que os moradores tiveram o real conhecimento que a região dos antepassados não pertencia mais à Áustria e sim à Itália. Essa constatação permitiu que se iniciasse um intercâmbio dos moradores do bairro com a região de Trento na Itália.

Mediante todo o contexto histórico do bairro é possível afirmar que o que sempre deu sustento econômico à comunidade foi a produção de cana-de-açúcar, que

\footnotetext{
7 Possui área aproximada de 20 hectares.

8 Não há informações e dados precisos sobre a quantidade de plantas ornamentais produzidas.

9 Represamento das águas do Ribeirão do Cascalho. n.a.
} 
mesmo sendo produzida por poucos moradores na atualidade, é o único cultivo em escala comercial.

Com os desmembramentos de terras, devido à divisão das heranças, muitas das propriedades não eram mais suficientes e inúmeros habitantes do bairro passaram a trabalhar na indústria da cidade de Piracicaba. Houve, também a partir da década de 1960, um aumento das terras arrendadas para a Usina, bem como a busca por trabalho na lavoura de outros proprietários.

Nas poucas propriedades que ainda há produção são arrendadas para dois moradores do Bairro que cultivam cana-de-açúcar com o uso de maquinários pertencentes a eles. A cana é comercializada com as usinas, ficando os proprietários das terras com $20 \%$ do valor da colheita.

Em Santana a produção de vinho sempre foi uma tradição, fosse a partir da uva comprada no Rio Grande do Sul, ação mais recente, ou a partir das próprias parreiras plantadas no fundo do quintal. Há também tentativas de cultivo de uva em três propriedades, mas a escala de produção é pequena e não atende à demanda da cooperativa de vinho que há no Bairro, A Coopervin. Essa tentativa de plantio da uva faz parte de um projeto maior que visa o resgate da tradição de agricultor entre os moradores mais jovens.

Nem mesmo as difíceis condições de infraestrutura no decorrer da história do bairro representaram um fator determinante para que as famílias de lá saíssem. A luz elétrica chegou à Santana na metade da década de $1950^{10}$, a água encanada na década de 1970, porém ainda há muitos moradores que utilizam poço artesiano. Parte dessa condição de não admitirem sair do bairro por nenhum motivo, é também em função da integração que há entre os habitantes e o desejo da conservação da cultura e do modo de vida.

O comércio do bairro hoje é constituído por uma cantina, um minimercado, uma vendam um bar e uma padaria, todos localizados no núcleo do Bairro. Santana ainda possui um posto de saúde que conta com a presença diária de uma médica e duas enfermeiras.

Dentre as tradições que resistiu ao tempo está o mutirão. Realizado de maneira ampla nas festas, ele também acontece em outras ocasiões, como na construção da igreja, do salão de festas e no centro da catequese.

\section{FUNÇÕES NOS BAIRROS}

A função como elemento analítico é relacionado com a tarefa ou atividade desempenhada pelo objeto (CÔRREA, 1986; SANTOS, 1985). Dentre as funções cumpridas pelos bairros na atualidade estão a religiosa e a cultural.

A igreja de Nossa Senhora da Assunção no bairro de Cascalho é para a comunidade muito mais do que um lugar para o desenvolvimento da prática religiosa, pois por meio dela se desenvolvem uma série de atividades e grande parte da sociabilidade do bairro. O mesmo acontece com a Igreja de Santana, no bairro de mesmo nome. Tantos os elementos visíveis, representados pelas edificações, presença de imagens nas entradas das residências, capelas e até mesmo o roteiro do caminho da

\footnotetext{
10 Por influência do vereador da época, Guilherme Vitti, que era nascido no Bairro.
} 
fé existente no bairro de Cascalho, como os não visíveis, evidenciados em determinadas ocasiões e horários do dia como o badalar do sino, os cânticos proferidos nas procissões e as rezas, representam uma demarcação do lugar, não deixando espaço para a prática de outras religiões ou seitas, que não a católica. Dessa forma, a igreja e sua fiel comunidade cumprem com a função religiosa.

É por meio das igrejas que também se sucedem a realização das festas. Durante os eventos é que acontece e transparecesse para as pessoas de fora outra função que os bairros adquiriram com o tempo, que é demonstrar as tradições e cultura. Como modo de tornar cada vez mais evidente essas tradições, sejam elas conservadas ou recuperadas, foram implementadas nos bairros a Associazione Trevisani Nel Mondo, em Cascalho e o Circolo Trentino di Piracicaba em Santana. Essas entidades visam promover e efetivar a cultura italiana, ou seja, a cultura dos antepassados que vieram para o Brasil e mesmo enfrentando muitas dificuldades as venceram deixando como herança e base: a família, o trabalho e a religião.

\section{CONSIDERAÇÕES FINAIS}

Dentre todos os elementos que fazem parte das características de um bairro rural, o sentimento de pertencimento é o que mais transpareceu quando foram realizadas as entrevistas. Isso foi facilmente evidenciado pelos relatos e quando aconteceram as práticas lúdico-religiosas e as festas. O relacionamento familiar também é tido como fator fundamental para a constituição do bairro, principalmente em Santana, onde uma grande parte da população é casada com parentes.

O mutirão, prática tão importante no passado, quando era necessário esse auxílio vicinal em função da atividade agropecuária, principalmente em época de colheita, hoje está restrito à execução das festas e de forma pontual quando acontece alguma obra da igreja. Essa mudança de ordem econômica nos bairros, na qual a população deixou de ser produtor rural para exercer outras funções e trabalhar em outras áreas, teve como consequência a o estreitamento das relações entre campo e cidade. Essa perda da função econômica acabou por destacar ainda a função religiosa e cultural.

A atuação das entidades dos bairros que visam promover a cultura italiana deixa explícito o desejo da perpetuação das tradições que se mantiveram com o tempo, e a busca pela recuperação de elementos que remetem às danças, os símbolos, as músicas e manifestações da cultura daquele país.

A função religiosa continua a ser muito estável e intensa nos bairros. A ocupação do lugar por meio dos símbolos, manifestações, práticas e eventos não permite a introdução de outra seita ou religião de forma notória que não a católica. 


\section{REFERÊNCIAS}

BOTTEON, Luiz Claudemir (Org.). Cascalho: imigrantes de ontem, brasileiros de hoje: álbum histórico dos 110 anos de imigração das famílias de Cascalho. São Paulo: Editora Ave-Maria, 2005.

CANDIDO, Antônio. Os Parceiros do Rio Bonito: estudo sobre o caipira paulista e a transformação dos seus meios de vida. 11. ed. Rio de Janeiro: Ouro sobre Azul, 2010.

CENTRO DE ANÁLISE E PLANEJAMENTO AMBIENTAL - CEAPLA. Atlas Ambiental da Bacia do Rio Corumbataí. Rio Claro, jan. 2011. Disponível em: <http:// ceapla2.rc.unesp.br/atlas> Acesso em: 16 abr. 2017.

CÔRREA, Roberto Lobato. Região e Organização espacial. São Paulo: Ática, 1986. DINIZ, José Alexandre Felizola. Cálculo da eficiência da agricultura na Depressão Periférica Paulista. Cadernos Rioclarenses de Geografia, Rio Claro, n. 1, p. 1-22, 1969.

FERNANDES, Liliana Laganá. Bairros Rurais do Município de Limeira: Estudo Geográfico. 1972. 251 f. Tese (Doutorado em Geografia). Departamento de Geografia, Universidade de São Paulo, São Paulo, 1972.

GADELHA, Regina Maria D'Aquino Fonseca. Os Núcleos Coloniais e o Processo de Acumulação Cafeeira (1850-1920): Contribuição ao Estudo da Colonização em São Paulo. 1982. 401 f. Tese (Doutorado em História) - Faculdade de Filosofia, Letras e Ciências Humanas da Universidade de São Paulo, São Paulo, 1982.

LEME, Maria Luísa de Almeida. Educação, Cultura e Linguagem: a comunidade tirolo-trentina da cidade de Piracicaba - SP. 2001275 f. Tese (Doutorado em Educação). Faculdade de Educação, Universidade Estadual de Campinas/UNICAMP, Campinas, 2001.

LEOPOLDINO, Everton Altmayer. O dialeto trentino da Colônia Tirolesa de Piracicaba: aspectos fonéticos e lexicais. 2014. 524 f. Tese (doutorado em Letras). Faculdade de Filosofia, Letras e Ciências Humanas, Universidade de São Paulo, São Paulo, 2014.

LOMBARDO, Magda Adelaide. Economia de Mercado e Organização do Espaço Agrário: o exemplo de Cordeirópolis. 1978. 138 f. Dissertação (Mestrado em Geografia) -Faculdade de Filosofia, Letras e Ciências Humanas, Universidade de São Paulo, São Paulo, 1978.

MÜLLER, Nice Lecocq. Bairros Rurais do Município de Piracicaba. Boletim Paulista de Geografia, São Paulo, n. 43, p. 83-130, jul. 1966.

ROLIM, Glauco de Souza et al. Classificação climática de Köppen e de Thornthwaite e sua aplicabilidade na determinação de zonas agroclimáticas para o Estado de São Paulo. Bragantia, Campinas, v. 66, n. 4, p. 711-720, 2007.

ROSS, Jurandyr. L. Sanches. Os fundamentos da Geografia da natureza. In:

Geografia do Brasil. 6 ed. São Paulo: Editora da Universidade de São Paul, 2009.

SANTOS, Milton. Espaço e Método. São Paulo: Nobel, 1985.

ULRICH, Sandra Regina Giraldelli. O mito recontado: um conto detonando a memória.

Teoria \& Prática. Limeira, v. 1, n. 2, p. 23-33, 2002. 